\title{
Activation of GRP78 on Endothelial Cell Membranes by an ADAM15-Derived Peptide Induces Angiogenesis
}

\author{
Annat Raiter ${ }^{\mathrm{a}}$ Chana Weiss $^{\mathrm{a}}$ Zafrir Bechor $^{\mathrm{a}} \quad$ Itzik Ben-Dor $^{\mathrm{b}} \quad$ Alexander Battler $^{\mathrm{b}}$ \\ Boris Kaplan ${ }^{c}$ Britta Hardy ${ }^{a}$ \\ ${ }^{a}$ Felsenstein Medical Research Center, Tel-Aviv University School of Medicine, ${ }^{b}$ Department of Cardiology and \\ 'Obstetrics and Gynecology, Rabin Medical Center, Beilinson Campus, Petach-Tikva, Israel
}

\section{Key Words}

Angiogenesis - HWRR motif • Heat shock GRP78 protein •

Endothelial cells $\cdot$ Ischemia model

\begin{abstract}
Impaired angiogenesis is one of the features of ischemic diseases. We have previously identified, by screening a phage display peptide library, a peptide that induces angiogenesis in endothelial cells under hypoxic conditions by binding the cell's membrane heat shock protein GRP78. Protein data base search identified 4 amino acids (HWRR) of that synthetic peptide present on the ADAM15 metalloprotease domain, a protein considered to be involved in neovascularization. Three peptides were synthesized according to the ADAM15 sequence placing HWRR at different positions. Peptide ADoPep1 exhibited significant angiogenic properties under hypoxic conditions as determined by cell proliferation, migration and tube formation. In a mouse hind limb ischemia model, a single injection of the peptide restored blood perfusion. The identified peptide was found to activate GRP78 on endothelial cell membrane and siRNA directed against the GRP78 mRNA interfered with induction of angiogenesis by the peptide. The peptide binding induced a decrease in heat shock protein GRP78 that is overexpressed under hypoxic conditions. The mechanism of peptide-induced an-
\end{abstract}

giogenic activity involves inhibition of apoptosis as well as increased Akt phosphorylation and ERK 1/2 activation. The peptide did not induce VEGF receptor-2 protein synthesis and phosphorylation, suggesting a VEGF-independent mechanism of angiogenesis. Copyright $\odot 2010$ S. Karger AG, Basel

\section{Introduction}

Impaired angiogenesis is one of the features of ischemic diseases. The most established target for therapeutic angiogenesis has been VEGF and its receptors [1]. However, clinical trials to alleviate ischemia were disappointing, indicating the need for new molecules and molecular targets to treat ischemic diseases [2]. By screening a combinatory phage display peptide library on endothelial cells under different physiological conditions, we have identified several different peptides. Selected peptides have been shown to induce angiogenesis using a mechanism independent of VEGF [3]. Further studies have demonstrated that one of these novel synthetic peptides, RoY (also designated as YR), induced angiogenesis under hypoxic conditions and alleviated hind limb ischemia in mice. This peptide was found to bind GRP78 heat shock protein on endothelial cell membranes [4].

\section{KARGER}

Fax +41613061234 E-Mail karger@karger.ch www.karger.com
(C) 2010 S. Karger AG, Basel

$1018-1172 / 10 / 0475-0399 \$ 26.00 / 0$

Accessible online at:

www.karger.com/jvr
Dr. Britta Hardy

The Felsenstein Medical Research Center

Tel-Aviv University School of Medicine, Rabin Medical Center

Beilinson Campus, Petach Tikva 49100 (Israel)

Tel. +972 3937 6782, Fax +972 3921 6979, E-Mail bhardy@post.tau.ac.il 
We therefore hypothesized that an alternative angiogenesis mechanism involves the GRP78 protein on endothelial cells. A protein database search identified the 4 amino acids of the RoY peptide His-Trp-Arg-Arg (HWRR) present on the metalloprotease domain of ADAM15, a disintegrin and metalloprotease protein 15, considered to be involved in neovascularization [5-9]. Mice lacking the ADAM15 gene exhibit a reduction in neovascularization, compared to wild-type controls. These reports suggest that ADAM15 has an important role in mediating neovascularization $[6,10,11]$. Furthermore, endothelial cell migration, a key feature of angiogenesis, was blocked by antibodies directed to ADAM15 and by the metalloprotease inhibitor BB3103, suggesting that the metalloprotease activity is essential for this process [12]. We therefore searched for the ADAM15-derived peptide that contains the 4 amino acids present in RoY peptide at different positions for evaluation of their angiogenic activity. Our aim was to select the best 'natural' 12-amino-acid peptides for future clinical application in ischemic diseases.

\section{Materials and Methods}

\section{Endothelial Cell Cultures}

Endothelial cells were isolated from human umbilical veins (conforming to the principles outlined in the Declaration of Helsinki for use of human tissues by Rabin Medical Center, Beilinson Hospital Ethics Committee) by collagenase digestion [13]. Cells were cultured on fibronectin-covered Petri dishes with endothelial cell growth medium (PromoCell, Heidelberg, Germany). Cells from 3-6 different cords on passages 3-4 were used for all experiments. Cultures were subjected to hypoxic conditions using a gas mix of $94 \%$ nitrogen $+5 \% \mathrm{CO}_{2}+1 \% \mathrm{O}_{2}$ in a hypoxia chamber (Billups-Rothenberg, Del Mar, Calif., USA).

\section{Peptide Synthesis}

The peptides ADoPep1, 2 and 3 were synthesized by GL Biochem Ltd. (Shanghai, China). The 5-amino-acid peptides (the common motif and the control motif) were synthesized by BiomerTechnology, tailor-made peptide solutions (Pleasanton, Calif., USA). Biotinylated ADoPep1 was synthesized by SynPep (Dublin, Calif., USA), with the addition of Biotin N-terminal Ahx, 6-aminohexanoic acid residue to the peptide sequence. HPLC purity was over $95 \%$ for each peptide synthesized.

\section{Cell Proliferation}

Cells were seeded on 24-well plates (12,000 cells/well) and cultured in endothelial cell growth medium for $24 \mathrm{~h}$. For starvation conditions, medium was replaced by supplement-free medium containing 5\% FCS. Peptides were added at 0.1, 1, 10 and $100 \mathrm{ng} /$ $\mathrm{ml}$ and cultures were incubated under hypoxic conditions for $24 \mathrm{~h}$ followed by $48 \mathrm{~h}$ under normoxic conditions or left for $72 \mathrm{~h}$ under normoxic conditions. Cells were pulsed with $\left[\mathrm{H}^{3}\right]$ thymidine
( $2 \mu \mathrm{Ci}$ /well) overnight, lysed by $15 \mathrm{~min}$ incubation with $300 \mu \mathrm{l} /$ well of $0.5 \mathrm{M} \mathrm{NaOH}$ at $37^{\circ} \mathrm{C}$ and counted in a beta counter. Results of 4 repeated experiments are expressed as the percent increase in thymidine uptake, in samples with peptides versus samples without peptides \pm SEM.

\section{Cell Migration}

Endothelial cell migration was evaluated with the Chemicon QCM 96-well migration assay kit (Chemicon International, Temecula, Calif., USA). A total of 25,000 cells per well were placed on the bottom of an 8 - $\mu \mathrm{m}$ pore size membrane under starvation conditions. ADoPep1, 2 and 3 as well as RoY peptides were added to the feeder tray at 1,10 and $100 \mathrm{ng} / \mathrm{ml}$ for $5 \mathrm{~h}$ under hypoxic conditions. Cells that migrated through the membrane were lysed by the addition of a buffer containing CyQuant GR dye and fluorescence was measured with an ELISA reader at 480/520 nm. Results of 3 repeated experiments are expressed as relative fluorescent units \pm SEM.

\section{Tube Formation}

Endothelial cells were incubated under starvation conditions for $24 \mathrm{~h}$. Samples of 50,000 cells in $500 \mu \mathrm{l}$ medium were transferred to 24 -well plates precoated with $250 \mu$ l Cultrex Basement Membrane Extract (with reduced growth factors; R\&D Systems, Minneapolis, Minn., USA). ADoPepl was added at the optimal concentration of $10 \mathrm{ng} / \mathrm{ml}$ (based on preliminary findings). The control peptide was added at the same concentration and the slides were examined by light microscopy after $6 \mathrm{~h}$ incubation. Photomicrographs were taken at original magnification $\times 40$. The length of the network of connected cells (tube formation) in 3 repeated experiments was measured in micrometers in 5 different areas of each well using Image-Pro Plus Image software (Media Cybernetics, Bethesda, Md., USA).

\section{Competitive Binding of Peptides by FACS}

Biotinylated ADoPep1 was used for staining endothelial cells cultured for $24 \mathrm{~h}$ under hypoxic conditions by adding $10 \mu \mathrm{g}$ per 100,000 cells for $2 \mathrm{~h}$ on ice followed by streptavidin-fluorescein isothiocyanate (FITC) (Jackson ImmunoResearch, West Grove, Pa., USA). For competitive binding assay, nonlabeled ADoPep1, 2 and 3 as well as the common motif and control peptides were added at 1.2, 5 and $10 \mu \mathrm{g} / \mathrm{ml}$ for $2 \mathrm{~h}$ on ice followed by the biotinylated ADoPep1. Samples were analyzed using a fluorescenceactivated cell sorter (FACScan; Beckton Dickinson, Franklin Lakes, N.J., USA). Results are expressed as percent binding of peptide $\pm \mathrm{SD}$

\section{Identification of the Membrane-Binding Protein}

Endothelial cells cultured in 90-mm Petri dishes for $24 \mathrm{~h}$ were exposed to normoxic or hypoxic conditions. To obtain enriched endothelial cell membranes, cells were warmed to $37^{\circ} \mathrm{C}$. Glycerol (90\%) was added to cells in 3 increments for 5 min each. Cells were transferred to ice immediately after the last glycerol addition. Cells were centrifuged for $10 \mathrm{~min}$ at $600 \mathrm{~g}$ and the pellet was resuspended in buffer lysate $(50 \mathrm{~mm}$ TrisCl pH $8,150 \mathrm{mM} \mathrm{NaCl}$, $0.02 \%$ Na-azide, $0.1 \%$ sodium deodocyl sulfate, $1 \% \mathrm{NP}-40,1 \mu \mathrm{g} /$ $\mathrm{ml}$ protease inhibitors, $100 \mu \mathrm{g} / \mathrm{ml}$ phenylmethylsulphonylfluoride). Lysates were centrifuged for $10 \mathrm{~min}$ at $700 \mathrm{~g}$ and supernatants $(50 \mu \mathrm{g} / 50 \mu \mathrm{l})$ were precleared with agarose-streptavidinbiotin and then precipitated with $10 \mu \mathrm{g}$ of biotinylated ADoPep1 
for $1 \mathrm{~h}$ at $4^{\circ} \mathrm{C}$. Streptavidin Sepharose beads (Amersham Biosciences, Uppsala, Sweden) were added to the samples for $1 \mathrm{~h}$ and subjected to polyacrylamide gel electrophoresis. The gel was stained with Coomassie blue, and the major band was cut and examined by mass spectrometry for identification of its protein content. The procedure for protein identification included digestion by trypsin and analysis by LC-MS/MS on LTQ-Orbitrap (Thermo, Waltham, Mass., USA) and identification by Pep-Miner and Sequest software against the human, mouse, rat, bovine and rabbit parts of the database.

\section{Western Blot Analyses}

Precipitated endothelial cell membrane lysates were analyzed by Western blot to verify that the protein precipitated binds ADoPep1. Nitrocellulose membranes were stained with either biotinylated ADoPep1 (5 $\mu \mathrm{g} / \mathrm{ml}$ in PBS-Tween) or goat anti-GRP78 polyclonal antibody (C-20; Santa Cruz Biotechnology, Santa Cruz, Calif., USA) and incubated with $1 \mu \mathrm{g} / \mathrm{ml}$ anti-HRP-conjugated streptavidin for the biotinylated peptide or anti-goat HRP for the antibody. Precipitated endothelial cell lysates were analyzed by Western blot in 4 different experiments to determine KDR protein by rabbit anti-KDR polyclonal antibody (Santa Cruz Biotechnology) followed by anti-rabbit HRP (Jackson ImmunoResearch). SuperSignal West Pico chemiluminescent substrate (Pierce, Rockford, Ill., USA) was used in all Western blot analyses. Quantification of protein was determined by densitometry (KDR/ actin ratio) employing the VersaDoc Imaging System (Bio-Rad Lab. Inc., Hercules, Calif., USA).

\section{Phosphorylation of VEGF Receptor 2 (KDR) by FACS}

Endothelial cell cultures were exposed to hypoxic conditions for $24 \mathrm{~h}$. ADoPepl at $10 \mathrm{ng} / \mathrm{ml}$ and VEGF used as positive control were added for 5, 15, 30 and $60 \mathrm{~min}$. Cell samples $(100,000)$ were transferred to FACS tubes and stained with anti phospho-KDR (R\&D Systems) for $1 \mathrm{~h}$ at $4^{\circ} \mathrm{C}$ followed by anti-rabbit FITC in 4 different experiments using endothelial cells from different cords.

\section{Akt1/2/3 and ERK1/2 Phosphorylation by ADoPep1}

Endothelial cells were incubated with $10 \mathrm{ng} / \mathrm{ml}$ of ADoPep1 for different times under hypoxic conditions. The reaction was stopped by replacing the medium with lysis buffer containing 50 $\mathrm{mM}$ Tris. $\mathrm{HCl}$ (pH 7.5), $120 \mathrm{~mm} \mathrm{NaCl}, 1 \%$ (v/v) Nonidet P-40, 25 $\mathrm{mM}$ sodium fluoride, $1 \mathrm{mM}$ sodium pyrophosphate, $0.1 \mathrm{mM}$ sodium orthovanadate, $1 \mathrm{mM}$ PMSF, $1 \mathrm{~mm}$ benzamidine and leupeptin $(20 \mu \mathrm{g} / \mathrm{ml})$. Cells were lysed for $10 \mathrm{~min}$ over ice and centrifuged at $8,000 \mathrm{~g}$ for $10 \mathrm{~min}$ at $4^{\circ} \mathrm{C}$. Samples containing equal amounts of protein were used for electrophoresis. The immunoblottting of membranes with antibodies specific for phosphorylation of Akt (phospho-Akt1/2/3, Ser473-R; Santa Cruz Biotechnology) and ERK (phospho-ERK; Santa Cruz Biotechnology) was performed according to the manufacturer's instructions. For specific phospho-Akt inhibition, endothelial cells were treated with LY 294002 at $10 \mu \mathrm{M}$ (Calbiochem, San Diego, Calif., USA) for 30 min before the addition of ADoPepl at $10 \mathrm{ng} / \mathrm{ml}$ for $30 \mathrm{~min}$ and for specific inhibition of ERK phosphorylation, U0126 inhibitor was used at the same conditions. Immunoblots were detected and quantified by ECL and phosphorimaging. The membranes were reprobed for the protein loading control actin. Quantification of protein was determined by densitometry (phospho-Akt or phos-
pho-ERK/Actin ratio) employing the VersaDoc Imaging System (Bio-Rad Lab. Inc.).

\section{Mouse Ischemic Hind Limb Model}

Female C57BL6/J mice aged 13-15 weeks were used as previously described $[4,14,15]$ and according to the Institutional Animal Care and Use Committee of Tel Aviv University conforming to the NIH Guide for the Care and Use of Laboratory Animals. In short, the external iliac artery was ligated and dissected in the anesthetized mice. One day after surgery, mice were divided into 5 groups, 6-8 mice in each group, as follows: Groups 1 and 2 were injected with 0.1 or $1 \mu \mathrm{g} /$ mouse ADoPep 1 peptide. Groups 3 and 4 were injected with ADoPep3 with 0.1 or $1 \mu \mathrm{g} / \mathrm{mouse}$. Group 5 (control) was injected with PBS. All injections were administered intramuscularly at a site close to the ligation. Mouse limbs were scanned with a Laser Doppler Imager (Perimed, Järfälla, Sweden) immediately after surgery and on postoperative days 7, 14 and 21. To analyze the results, we gated the entire limb, including the foot. The median perfusion of each limb was determined, and the ratio between the ischemic (right) and the control, nonoperated (left) limb (relative perfusion) was calculated. A total of 3 experiments were performed.

\section{Histology of Mouse Hind Limbs}

On days 7, 14 and 21, three animals in each group were euthanized, and each leg was cut into thigh and calf for preparation of paraffin blocks for histological analysis, as previously described $[4,16]$. Sections of muscle samples were taken from the same areas in both the control and treated mice. Sections obtained from the calf were stained with rabbit anti-mouse von Willebrand factor (DakoCytomation) and the capillaries were visualized with the Envision+ system HRP kit (DakoCytomation). Capillaries were counted under a microscope in a total of 10 random fields from different sections. Density was expressed as the mean number of capillaries per field of view. Rabbit polyclonal antibody GRP78 (Thermo) was used to stain GRP78-positive cells followed by anti rabbit HRP. Apoptotic cells in the same sections were identified by the use of Apoptag peroxidase in situ detection kit (Chemicon). GRP78-positive cells and apoptotic cells were counted under a microscope from a total of 10 randomly chosen fields.

\section{Apoptosis and Membrane GRP78 by FACS Analysis}

For the induction of apoptosis, endothelial cells from 4 different cords in 4 separate experiments were exposed to $24 \mathrm{~h}$ hypoxia in starvation conditions. ADoPep1 (10 ng/ml) or anti GRP78 antibody $1 \mu \mathrm{g} / \mathrm{ml}$ (Santa Cruz Biotechnology) was added to cultures. Cells were harvested and stained with Human Annexin V-FITC kit (Bender Medsystems, Vienna, Austria) following the manufacturer's instructions. For GRP78 binding to endothelial cell membranes, endothelial cells were incubated, after hypoxia, with ADoPep1 at $10 \mathrm{ng} / \mathrm{ml}$ for 1, 5, 15, 30 and $60 \mathrm{~min}$ (4 experiments). Biotinylated ADoPep1 was added for $2 \mathrm{~h}$ for staining endothelial cells by the addition of $10 \mu \mathrm{g}$ per 100,000 cells on ice followed by streptavidin-FITC (Jackson ImmunoResearch).

\section{Silencing RNA of GRP78 Expression}

RNA interference of GRP78 expression was induced with small interfering RNA (siRNA) directed against the GRP78 mRNA. A pool of three different nucleotide siRNA specific primers were made to target human GRP78 mRNA sequence. The 
Table 1. Amino acid sequences of peptides derived from ADAM15

\begin{tabular}{lll}
\hline ADAM15 protein-derived peptides & Amino acid number \\
\hline Metalloprotease domain & & $207-696$ \\
ADoPep1 & His, Trp, Arg, Arg, Ala, His, Leu, Leu, Pro, Arg, Leu, Pro & $286-297$ \\
ADoPep2 & Glu, Asn, Phe, Leu, His, Trp, Arg, Arg, Ala, His, Leu, Leu & $282-293$ \\
ADoPep3 & Ala, Val, Thr, Leu, Glu, Asn, Phe, Leu, His, Trp, Arg, Arg & $279-290$ \\
Common motif & His, Trp, Arg, Arg, Pro & \\
Control peptide & Ala, His, Leu, Leu, Pro & \\
\hline
\end{tabular}

siRNAs started at position 139 (AAC GGC CGC GUG GAG AUC AUC), position 1,175 (AAG CUG UAG CGU AUG GUG CUG), and position 1,567 (AAG AUC ACA AUC ACC AAU GAC). A scrambled siRNA from position 1,567 was used as negative control. All oligonucleotides were from Santa Cruz Biotechnology. Endothelial cells were seeded at a density of 100,000 cells $/ \mathrm{cm}^{2}$ the day before transfection and were $80 \%$ confluent when they were transfected with $50 \mathrm{nmol} / \mathrm{l}$ positive or scramble oligonucleotides in SiRNA transfection medium and siRNA transfection reagent (Santa Cruz Biotechnology). The cells were transfected for $4 \mathrm{~h}$ in transfection medium.

In migration studies, GRP78 siRNA-transfected or scrambled siRNA-transfected endothelial cells (25,000 per well) were transferred to Boyden chambers, placed on the bottom of an $8-\mu \mathrm{m}$ pore size membrane under starvation and hypoxic conditions. ADoPep1 was added to the feeder tray at $10 \mathrm{ng} / \mathrm{ml}$ for $5 \mathrm{~h}$. Cells that migrated through the membrane were transferred to a 96 well plate and counted by XTT following the manufacturer's instructions (Biological Industries, Beit Haemek, Israel). Results are presented as mean of 3 repeated experiments in triplicates $\pm \mathrm{SD}$.

\section{Statistical Analysis}

Analysis of variance and the Tukey-Kramer honestly significant difference test for multiple comparisons were used for the statistical analysis. Results were considered significant at $\mathrm{p}<0.05$. JMP software (SAS Institute, Cary, N.C., USA) was used for data management and analyses.

\section{Results}

\section{Sequences of ADAM15 Metalloprotease}

Domain-Derived Peptides

A bioinformatics and computerized data search revealed that ADAM15 metalloprotease domain contains a minor similarity of 4 amino acids previously identified in the synthetic RoY peptide [4]. Three 12-amino-acid peptides from the ADAM15 protein area according to the sequences presented in table 1 were synthesized and designated as ADoPep1, 2 and 3. ADoPep1, 2 and 3 are derived from the amino acid sequence number 279-297 of the metalloprotease domain. Two 5-amino-acid peptides were also prepared; one that included the identical 4 amino acids His-Trp-Arg-Arg present in all ADoPeps with the ending of proline and a second 5-amino-acid control peptide that included 4 other amino acids that are present in ADoPepl and 2 (Ala, His, Leu, Leu) with the ending of proline (table 1).

\section{ADAM15-Derived Peptides Induce Angiogenesis}

To evaluate the angiogenic properties of ADAM15 metalloprotease-derived peptides (ADoPep1, 2 and 3) compared to RoY, we studied 3 well-established angiogenic parameters: proliferation, migration and tube formation. Figure la summarizes the net $\left[\mathrm{H}^{3}\right]$ thymidine uptake (as cpm above control without peptides) of cells cultured with different peptide concentrations. ADoPepl at $10 \mathrm{ng} / \mathrm{ml}$ induced a 1.8-fold increase over ADoPep2 and a 1.6-fold increase over ADoPep3 similar to the induction of proliferation by RoY peptide. At $100 \mathrm{ng} / \mathrm{ml}$, the proliferation of hypoxic endothelial cells with ADoPep1 reverted to values similar to the other peptides. Figure $1 \mathrm{~b}$ represents migration of endothelial cells induced by the 3 peptides in comparison to RoY peptide. The migratory chambers were cultured under hypoxic conditions with endothelial cells and the peptides in increasing concentrations as chemoattractants. Significant migration $(\mathrm{p}<$ 0.05 ) was induced by ADoPepl at $10 \mathrm{ng} / \mathrm{ml}$, similar to the effect of RoY peptide. As illustrated in figure 1c, ADoPepl added to endothelial cells cultured on Matrigel under hypoxic conditions for $6 \mathrm{~h}$ resulted in a significantly broader network of cells (502.71 $\pm 54 \mu \mathrm{m}$ length) compared to untreated cells (91.56 $\pm 13 \mu \mathrm{m}$ length).

\section{Peptides Bind GRP78 Protein on Endothelial Cells}

We analyzed the binding specificity of the ADoPepl, 2, 3 and the two short peptides to endothelial cells by inhibiting the binding of biotinylated ADoPepl by nonlabeled peptides. Figure 2a summarizes the results of a fluorocytometric analysis that determine the percent 


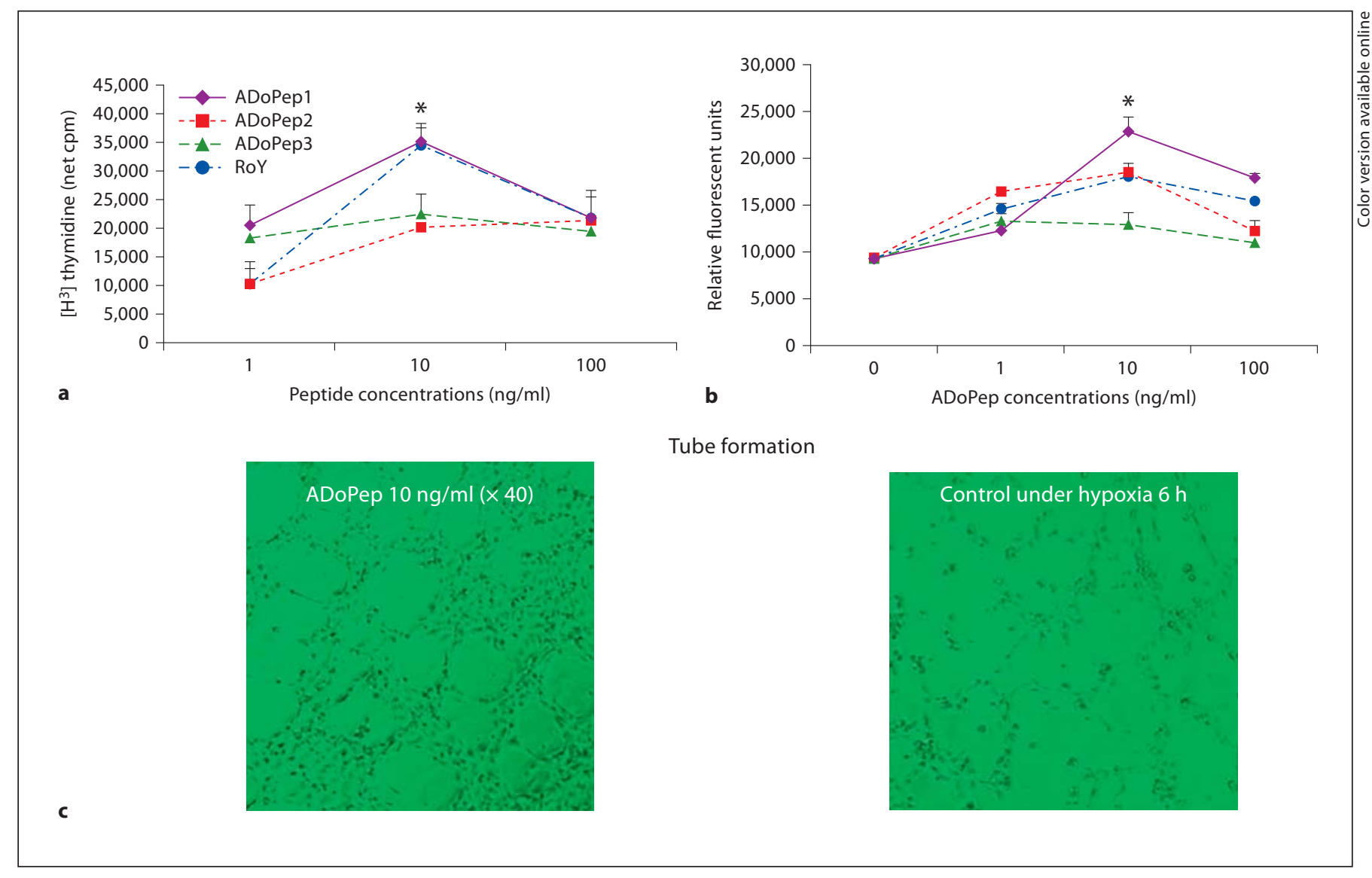

Fig. 1. Angiogenesis induced by peptides. The angiogenic properties of ADAM15-derived peptides were evaluated by endothelial cell proliferation, migration and tube formation under hypoxic conditions. a Proliferation was measured by $\left[\mathrm{H}^{3}\right]$ thymidine uptake on endothelial cell cultures with different concentrations of peptides. Net cpm in cells incubated with ADoPep1 over control was significant $\left.{ }^{*} \mathrm{p}<0.05\right)$ at $10 \mathrm{ng} / \mathrm{ml}$ in comparison to ADoPep2 or 3 . Values are means \pm SEM of 4 different experiments. $\mathbf{b}$ Mi-

binding of biotinylated ADoPep1 to endothelial cells. ADoPep1 binds $87.9 \pm 2.55$ (percent \pm SD), while increasing concentrations of nonlabeled ADoPep1 resulted in the inhibition of binding from $72.5 \pm 0.1$ to $37.85 \pm$ 6.8 with $1.2 \mu \mathrm{g} / \mathrm{ml}$ and $10 \mu \mathrm{g} / \mathrm{ml}$ of the peptide, respectively. The control peptide at $10 \mu \mathrm{g} / \mathrm{ml}$ did not compete for binding to the receptor $(73.4 \pm 7.3)$. The percent inhibition by ADoPep2, 3 and common motif at $10 \mu \mathrm{g} / \mathrm{ml}$ were $43.8 \pm 7,36.7 \pm 6.8$ and $34.5 \pm 4.3$, respectively, suggesting that ADoPep1, 2 and 3 and the common motif compete for the same receptor. We identified the GRP78 protein after two repeated analyses of the precipitated protein. To confirm that this band was indeed the peptide-binding protein, we stained Western blot membranes gration of endothelial cells incubated with peptides was quantified by the relative fluorescent unit of cells migrating in modified Boyden chambers. A significant increase $\left({ }^{*} \mathrm{p}<0.05\right)$ in endothelial cell migration was induced by $10 \mathrm{ng} / \mathrm{ml}$ ADoPep1 peptide in comparison to ADoPep2 and 3. Values are means \pm SEM of 3 different experiments. c Representative images of endothelial cell tube formation in Matrigel with ADoPep1 (10 ng/ml for $6 \mathrm{~h})$ and with the addition of control peptide. $\times 40$. with biotinylated ADoPep1 and antiGRP78 antibodies. Figure $2 \mathrm{~b}$ demonstrates the staining of the $78-\mathrm{kDa}$ bands by either the biotinylated peptide or the antibody. The bands obtained from lysates of endothelial cells under hypoxia contained almost 5 -fold more protein.

\section{Angiogenesis in a VEGF-Independent Mechanism}

To determine whether ADoPep1, that binds GRP78 on endothelial cells, induces angiogenesis in an VEGF-independent mechanism, we studied the activation of VEGF receptor 2 (KDR) by ADoPep1. Endothelial cells cultured with ADoPepl under hypoxic conditions did not induce a KDR protein increase. Figure 3a illustrates the Western blot of KDR in cultures with and without ADoPep1, 
Fig. 2. Peptides binding GRP78. a Competitive assay of ADoPep1, 2 and 3 and the common motif to bind to endothelial cells under hypoxic conditions by FACS analysis. Endothelial cells were incubated with peptides ADoPep1, 2 and 3 and the common motif at different concentrations followed by biotinylated ADoPepl. Control peptide did not compete for the same receptor with ADoPep1. Summary of 3 repeated experiments demonstrating significant $\left({ }^{*} \mathrm{p}<0.05\right)$ inhibition of binding of biotinylated ADoPep1 with the addition of $10 \mu \mathrm{g} / \mathrm{ml}$ of ADoPep and common motif. Values represent mean \pm SD of percent binding. b ADoPep1 binds GRP78 protein on endothelial cells. Western blot analysis of polyacrylamide gel electrophoresis of endothelial cell membrane lysates precipitated with ADoPep1 $(10 \mu \mathrm{g} / 500 \mu \mathrm{g}$ protein). Staining with anti GRP78 antibody $(2 \mu \mathrm{g} / \mathrm{ml})$ (left blot) demonstrated a 5-fold increase in the band of protein under hypoxic conditions. Staining with biotinylated ADoPep1 $(10 \mu \mathrm{g} / \mathrm{ml})$ (right blot) demonstrated similar results.

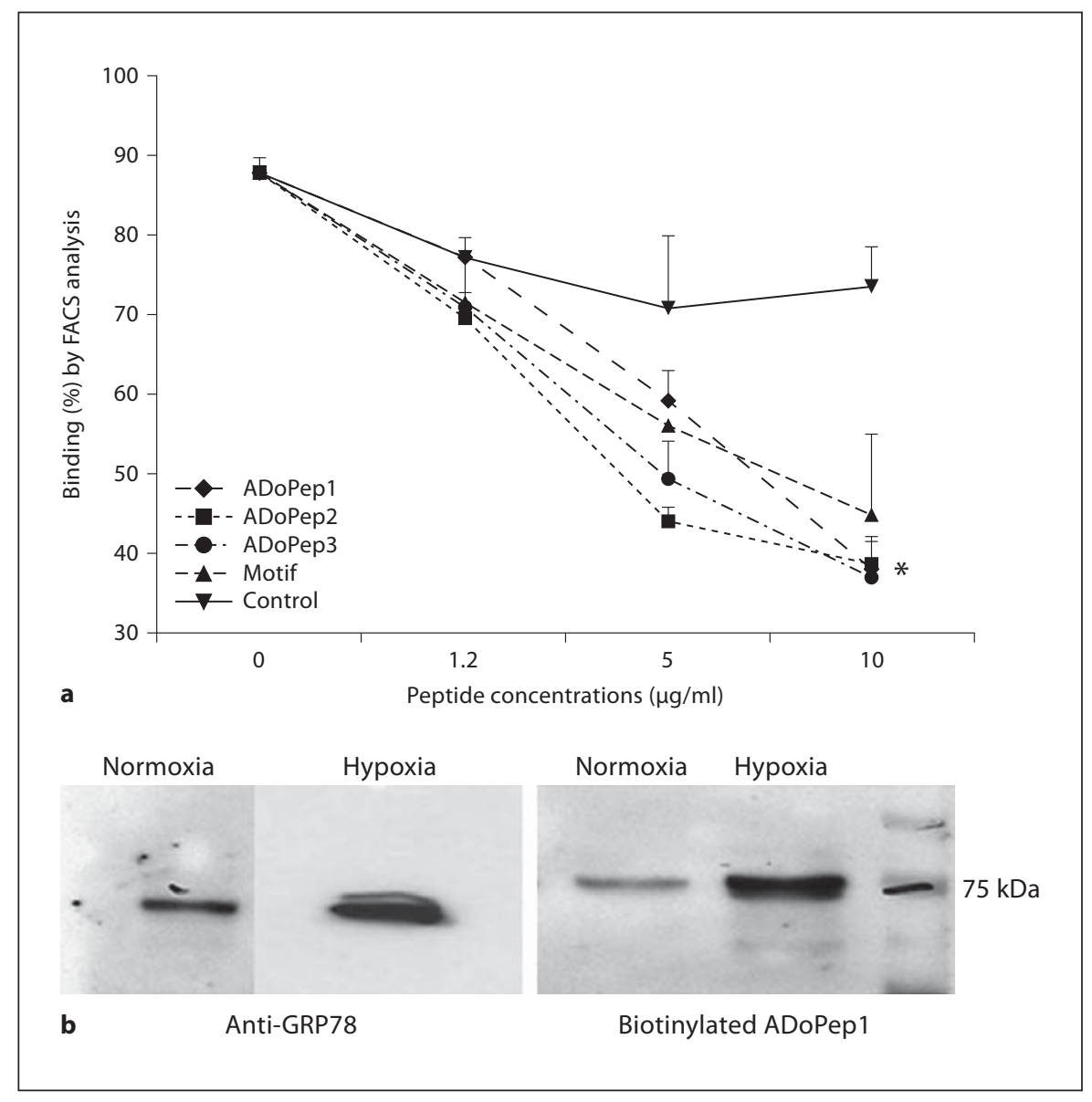

showing no change in KDR volume in 4 different experiments. We have also studied KDR phosphorylation by fluorocytometric analysis (fig. 3b) using anti-phosphoKDR. Phosphorylation of KDR was determined after 15 min incubation with either ADoPepl or VEGF in 4 separate experiments. ADoPep1 did not induce KDR phosphorylation in contrast to VEGF. The percentage of phosphorylated KDR was $3.51 \pm 0.3$ by ADoPepl compared to $45.82 \pm 2.3 \%$ when activated by VEGF.

\section{Alleviation of Ischemia by ADoPep1}

In order to assess the therapeutic effect of ADoPep1, we used the mouse hind limb ischemia model, previously described for the evaluation of angiogenic factors in therapeutic angiogenesis. The effect of a single intramuscular injection of ADoPep1 and 3, in restoring blood perfusion, was studied. Figure $4 \mathrm{a}$ summarizes the results of 3 repeated experiments with 6-8 mice per group, indicating that ADoPep1 at $0.1 \mu \mathrm{g} /$ mouse significantly $(\mathrm{p}<0.01)$ alleviated hind limb ischemia and restored relative blood perfusion $(0.99 \pm 0.03)$ to normal 21 days after operation. ADoPep at $1 \mu \mathrm{g} /$ mouse induced lower, though significant, values $(0.85 \pm 0.05, \mathrm{p}<0.01)$, while the relative blood perfusion obtained by the injection of ADoPep3 at $0.1 \mu \mathrm{g} /$ mouse or $1 \mu \mathrm{g} /$ mouse was similar to control PBS $(0.73 \pm 0.012)$ after 3 weeks. The Laser Doppler imager scans shown in figure $4 \mathrm{~b}$ were obtained on the day of operation and 21 days after treatment.

\section{Histology of Ischemic Limb Treated with ADoPep1}

Figure 5 demonstrates the histological examinations of ischemic legs 1 week after treatment. Figure 5 a presents capillary density (number of capillaries per $\mathrm{mm}^{2}$ ) that was examined by staining with von Willebrand factor. ADoPepl treatment significantly increased $(p<0.05)$ the number of capillaries 1 week after treatment from 62.53 \pm 9 (in control) to $137 \pm 42$ per $\mathrm{mm}^{2}$. The number of capillaries was sustained in the ADoPep1-treated mice 2 and 3 weeks after operation $(146.3 \pm 6.1$ on day 14 and $144.3 \pm 45$ on day 21$)$. Histological sections were also 
Fig. 3. ADoPep1 peptide does not induce KDR protein synthesis and phosphorylation. a Western blot analyses of KDR expression in endothelial cells cultured with and without the addition of ADoPep1. Average KDR/actin density \pm SD of 4 independent assays are presented. b Representative flow cytometry analysis showing the induction of KDR phosphorylation after 15 min incubation with VEGF compared to ADoPep1 that did not induce KDR phosphorylation.

Fig. 4. Peptide treatment of mouse hind limb ischemia. Ischemia was induced by femoral artery excision of the right leg and measured by a Laser Doppler imager immediately after surgery and 7, 14, and 21 days later to determine the ratio of the operated leg versus the nonoperated leg in 5 groups each containing 6-8 mice. a A single intramuscular injection of ADoPep1 at 0.1 and $1 \mu \mathrm{g} /$ mouse significantly alleviated hind limb ischemia on day 21 after operation ( $\left.{ }^{*} \mathrm{p}<0.01\right)$ compared to PBS. ADoPep 3 did not induce increased perfusion compared to control PBS. Values are means \pm SEM. $\mathbf{b}$ Representative images of the Laser Doppler show the nonoperated (right) and operated treated leg (left) at the day of operation and at 21 days after operation of ADoPep1 treated versus PBS control mice.
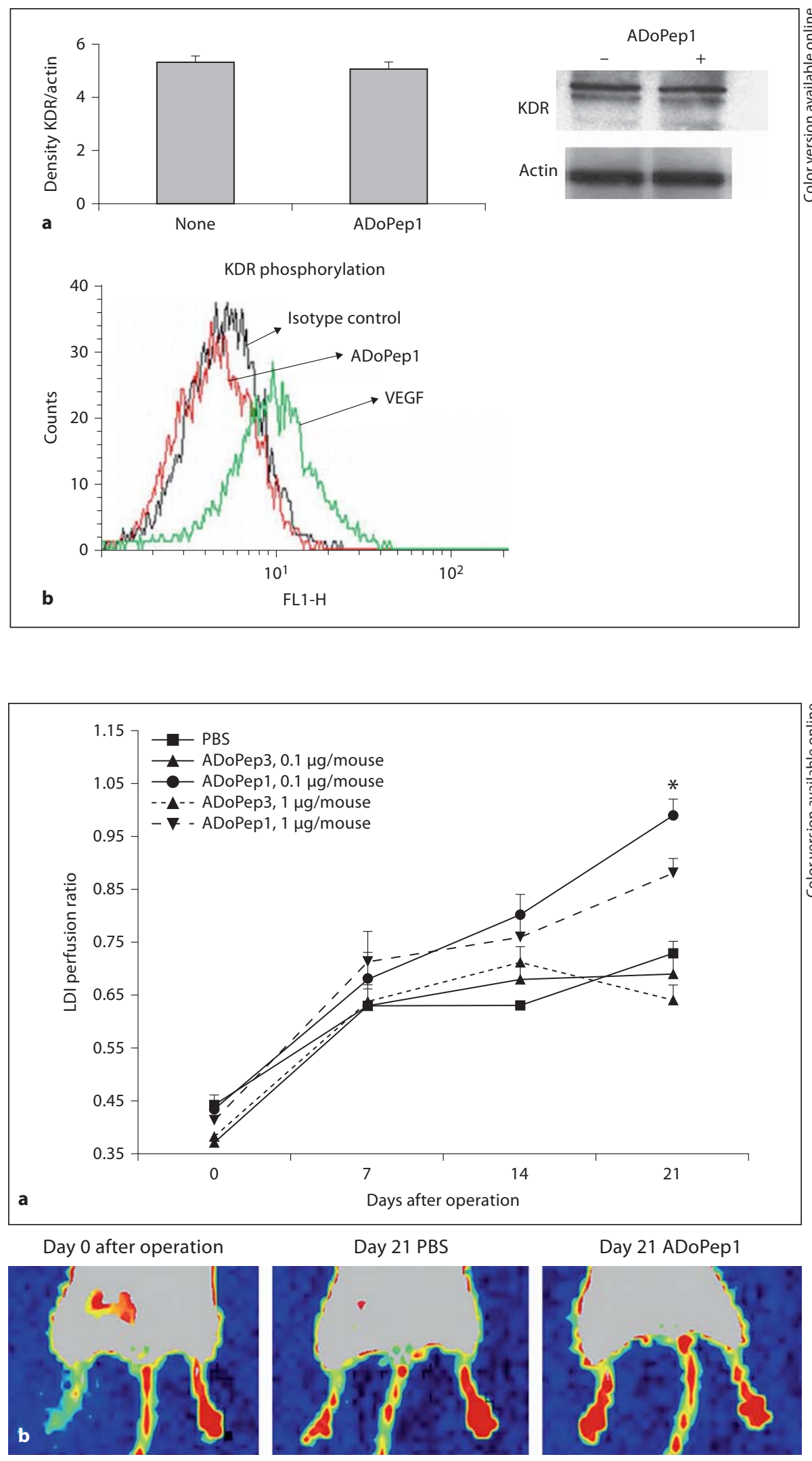

Day 21 ADoPep 1

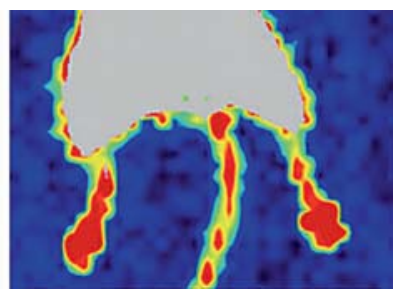




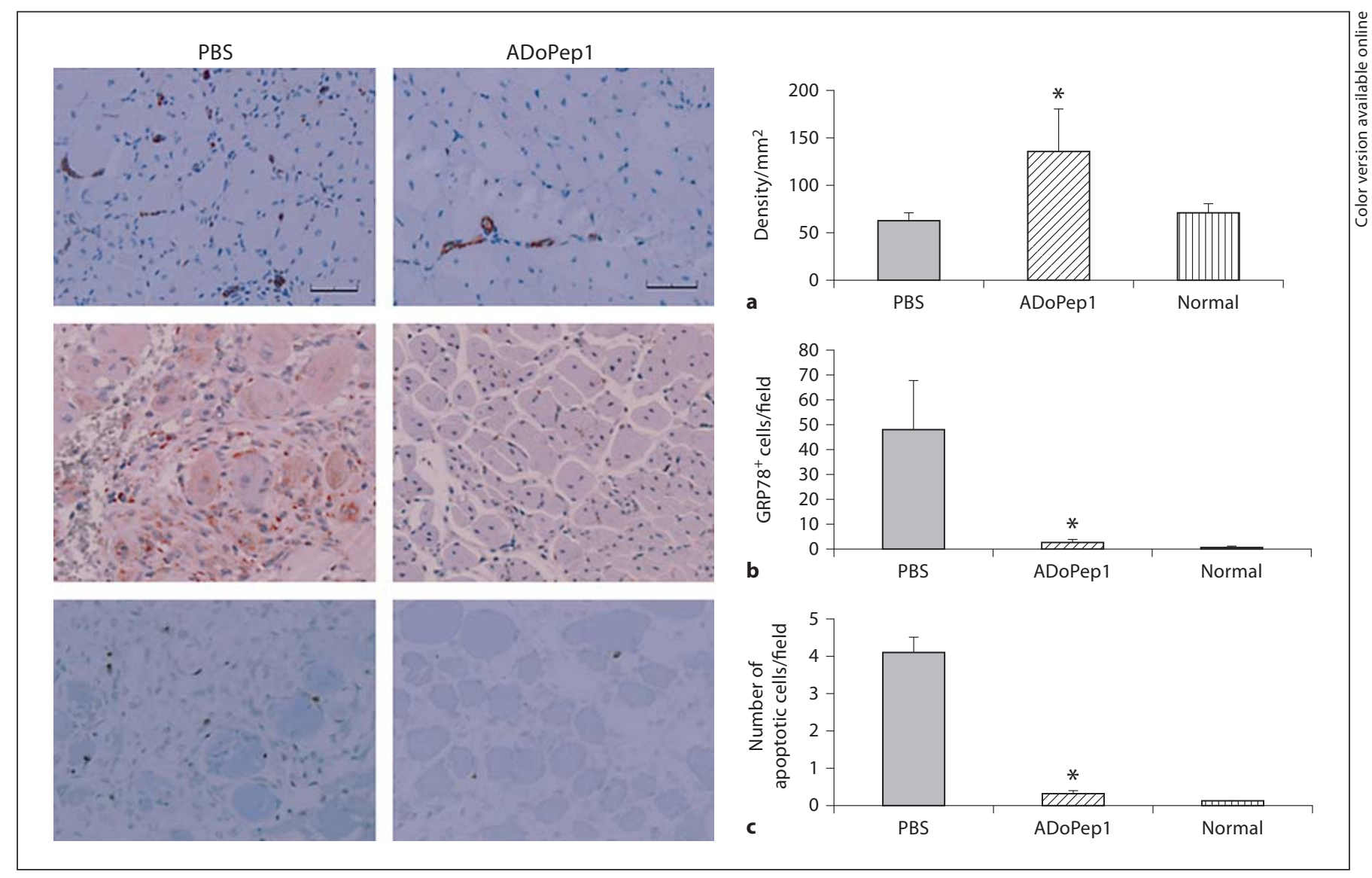

Fig. 5. Histology of peptide-treated mouse hind limb ischemia. Histological assessment of angiogenesis in C57BL mice ischemic hind limb 7 days after treatment with ADoPep1. a Factor VIII staining was used to quantify mean capillary density in sections of muscle samples taken from the same areas in both the control and treated mice. Mean capillary density in a total of 10 random fields from different sections were analyzed. Right: mean density \pm SEM of samples from mice treated with $0.1 \mu \mathrm{g}$ ADoPepl compared to control PBS were significantly higher $\left({ }^{*} \mathrm{p}<0.05\right)$. Left: representative sections from limb of PBS- and ADoPep1-treated mice 7 days after operation. Scale bar $=100 \mu \mathrm{m}$. b Determination of the number of apoptotic cells in histological sections stained with Apoptag. Apoptotic cells counted in a total of 10 random fields from different sections. Right: mean number \pm SEM of apoptotic cells from mice treated with $0.1 \mu \mathrm{g}$ ADoPepl compared to control PBS were significantly lower $\left({ }^{*} \mathrm{p}<0.05\right)$. Left: representative stained sections showing apoptotic cells. c Right: mean number \pm SEM of GRP78-positive cells from mice treated with $0.1 \mu \mathrm{g}$ ADoPep1 compared to control PBS were significantly lower $\left({ }^{*} \mathrm{p}<0.05\right)$. The number of cells counted in a total of 10 random fields from different sections. Left: representative photographs of treated and controls stained with antiGRP78. stained with anti GRP78 antibody present in all cells as a major chaperone, and therefore staining was not limited to endothelial cells. In contrast, GRP78 staining as determined by FACS analysis was not restricted to membranes but also intracellular GRP78. As can be seen in figure 5b, GRP78 was induced by ischemic conditions. The number of GRP78-positive cells per field decreased after 1 week of treatment with ADoPep1 from $47.4 \pm 20$ (control) to $2.6 \pm 1$ per field. Histological sections were also stained for the presence of apoptotic cells in the ischemic tissues. Figure $5 \mathrm{c}$ demonstrates histological sections stained for cells undergoing apoptosis. In the control untreated ischemic leg sections, the number of apoptotic cells decreased from $4.1 \pm 0.05$ (control) to $0.3 \pm 0.4$ after 1 week of ADoPep1 treatment.

\section{ADoPep1 Inhibits Hypoxia-Induced Apoptosis}

The effect of $10 \mathrm{ng} / \mathrm{ml} \mathrm{ADoPepl}$ and anti GRP78 antibody at $1 \mu \mathrm{g} / \mathrm{ml}$ on endothelial cell apoptosis was studied by fluorocytometric analysis using annexin $\mathrm{V}$ and propidium iodide. Apoptosis was determined by the percentage of the double-labeled cells. As can be seen in fig- 
Fig. 6. Inhibition of hypoxia-induced apoptosis and a decrease in peptide-induced GRP78 membrane. FACS analysis of hypoxia-induced apoptosis $24 \mathrm{~h}$ after hypoxia and inhibition of apoptosis in the presence of either ADoPep1 or antiGRP78 antibody is presented (upper). Apoptosis was determined by annexin V/PI. ADoPepl and Anti GRP78 inhibited in $40 \%\left({ }^{*} \mathrm{p}<0.01\right)$ of apoptosis as demonstrated in the summary of 4 experiments (lower). b FACS analysis of membrane GRP78 percent binding to endothelial cells exposed to hypoxia for $24 \mathrm{~h}$ and incubated with ADoPep1 for 1, 5, 15, 30 and $60 \mathrm{~min}$. The percent of GRP78-positive cells decreased significantly $\left({ }^{*} \mathrm{p}<0.05\right)$ after 15 min of ADoPep1 addition. Average mean GRP78 percent binding relative values $\pm \mathrm{SD}$ of 4 independent assays is presented.
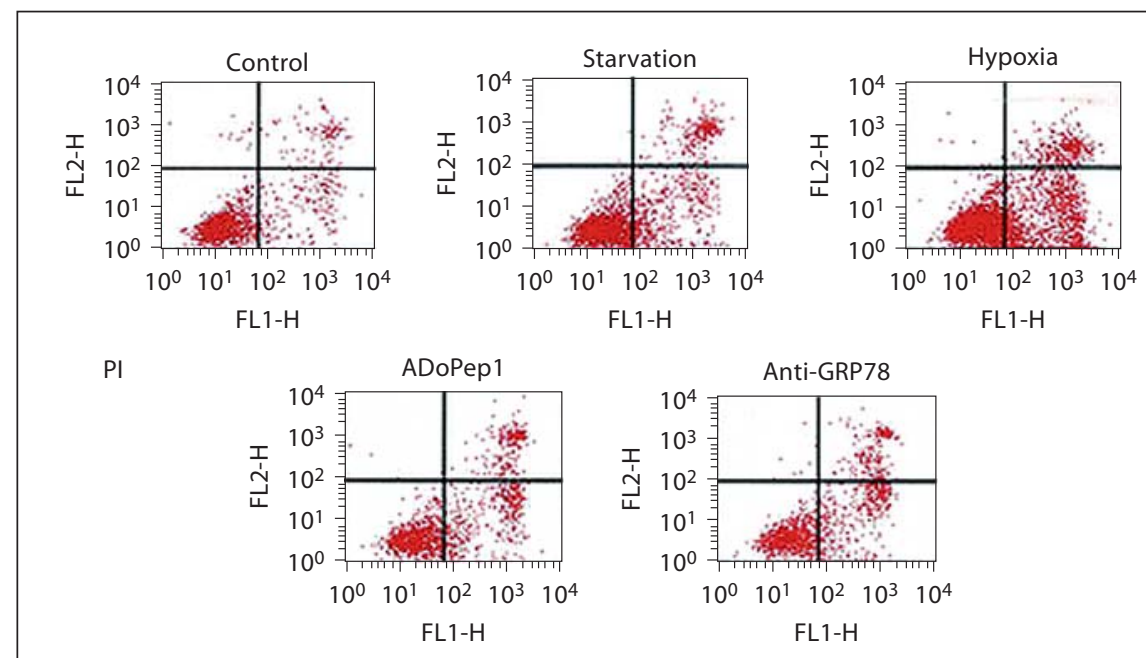

a

Annexin V
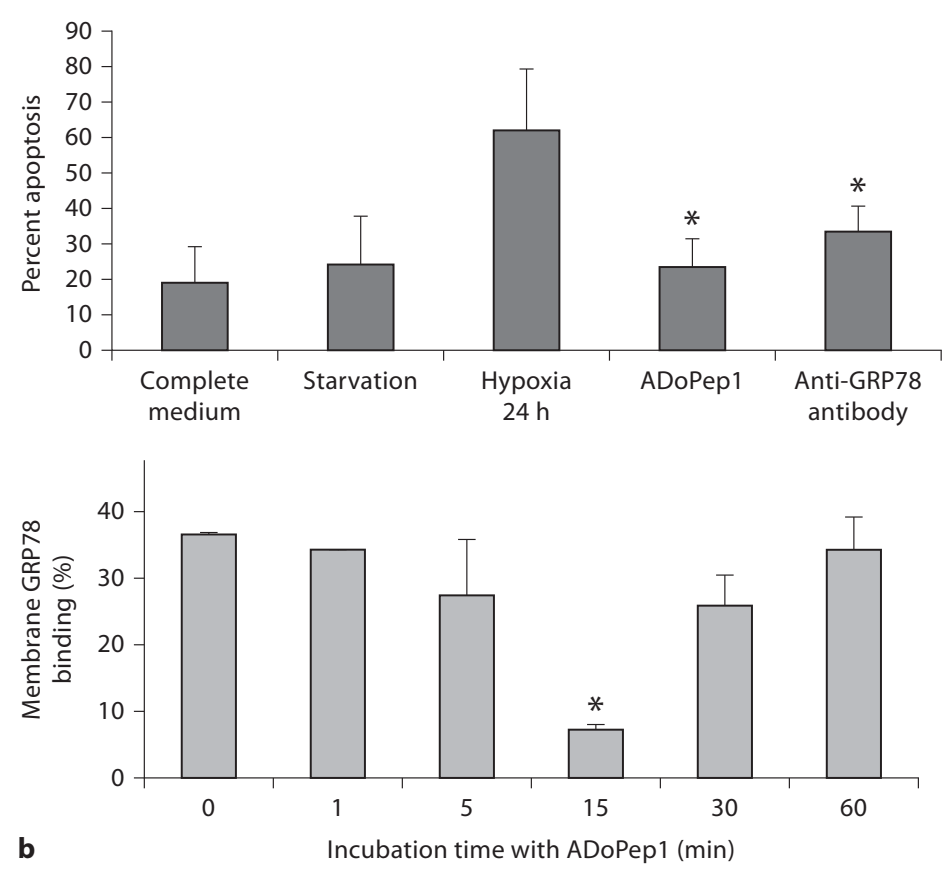

ure 6a, the percentage of untreated cells cultured in complete medium or incomplete medium (containing only $5 \%$ FCS) under normoxic conditions was $19.5 \pm 9.8$ and $24.8 \pm 13.4$, respectively. Incubation under hypoxic conditions induced $62 \pm 17.2$ percent apoptosis that decreased in the presence of either ADoPepl or anti-GRP78 to $23.2 \pm 7.3$ and $33.7 \pm 6.9$, respectively, representing 62 and $46 \%$ inhibition of hypoxia-induced apoptosis. ADoPep1 did not inhibit $\mathrm{CoCl}_{2}$-induced apoptosis (67 \pm 3 compared to $68 \pm 3.2$ ) (figure not shown). Figure $6 \mathrm{~b}$ summarizes 4 experiments using 4 different cords, 15 min after ADoPepl addition: the percentage of membrane GRP78 decreased significantly $(p<0.05)$. Data are shown as mean $\pm \mathrm{SD}$.

\section{ADoPep1 Induces an Increase in Akt and ERK1/2 \\ Phosphorylation}

Incubation of endothelial cells under hypoxic conditions with $10 \mathrm{ng} / \mathrm{ml}$ of ADoPep1 elevated phospho-Akt at about $30 \mathrm{~min}$ and remained elevated during $60 \mathrm{~min}$ of incubation (fig. 7a). In similar cultures, ADoPep1 also upregulated activation of ERK1/2 and induced the phos- 
Fig. 7. Signal transduction induced by ADoPep1 binding to GRP78. ADoPep1 activates phospho-Akt and phospho-ERK1/2 in endothelial cells under hypoxic conditions. a Changes in phospho-Akt over time in 1 representative out of 3 individual immunoblot experiments in which equal loading of protein was demonstrated by control actin determination. Values density ratio defining increase in Akt phosphorylation in ADoPep1incubated cells $(10 \mathrm{ng} / \mathrm{ml})$ compared to control without the peptide. b Changes in phospho-ERK1/2 over time are demonstrated in similar endothelial cell cultures with the addition of ADoPep1 for different times. c Representative immunoblot experiment showing inhibition of Akt and ERK phosphorylation by specific inhibitor in endothelial cells pre-incubated with MEK and PI3K inhibitors and followed by incubation with ADoPep1 for $30 \mathrm{~min}$.

phorylation of ERK1/2 after only 5 min incubation maintained for up to $60 \mathrm{~min}$ (fig. 7b).

Phospho-ERK-1 and 2 increased after 20-30 min activation with ADoPepl. Phosphorylation of Akt was reduced by $77 \%$ when cells were previously exposed to the phosphatidylinositol 3-kinase (PI3K) LY294002. In cells incubated with ADoPep, the phosphorylation of Akt was reduced in $83 \%$. Phosphorylation of ERK was reduced by $83 \%$ when cells were previously exposed to the MEK inhibitor U0126. Phosphorylation of ERK with the same inhibitor in cells incubated with ADoPepl was reduced by $67 \%$ (fig. $7 \mathrm{c}$ ).

\section{GRP78 siRNA}

The expression of GRP78 on endothelial cells was significantly reduced by $71 \%$ by the transfection of a siRNA for GRP78, but not by the transfection of a scrambled siRNA demonstrated by Western blot analysis (fig. 8a).

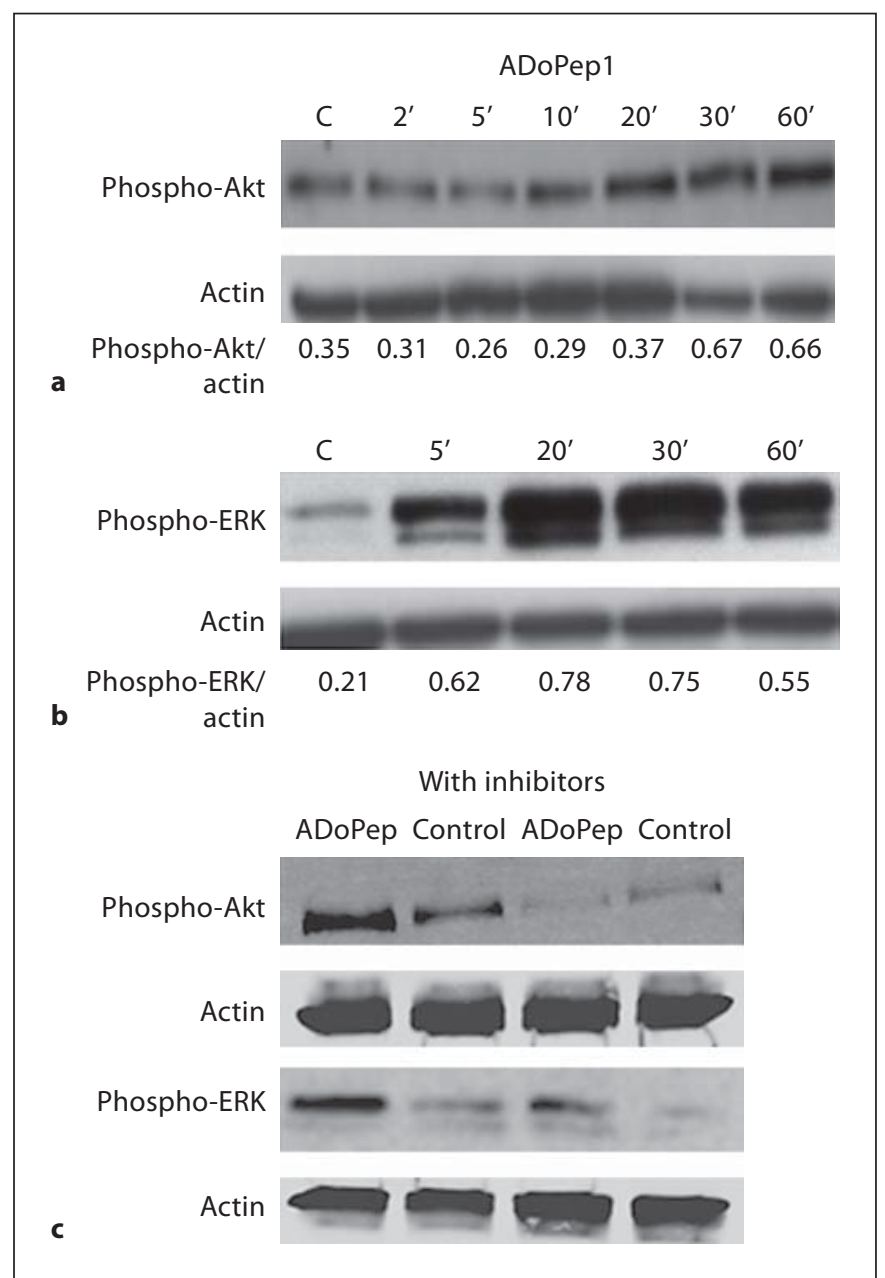

We demonstrated that ADoPep1 did not induce migration in endothelial cells cultures transfected with GRP78 siRNA in comparison to cells transfected with scrambled siRNA $(p<0.05)$. The results of 3 independent experiments in triplicate are presented in figure $8 \mathrm{~b}$.

\section{Discussion}

The major finding of the present study is the identification of 4 amino acids His-Trp-Arg-Arg (HWRR) present in peptides that induce angiogenesis; RoY, derived from a combinatory phage display peptide library, and ADoPep1, derived from the ADAM15 metalloproteinase domain. In preliminary experiments we studied the effect of two commercially available ADAM15 recombinant proteins (Af21 derived, NSO derived) on endothelial cell proliferation. However, the presence of ADAM15 


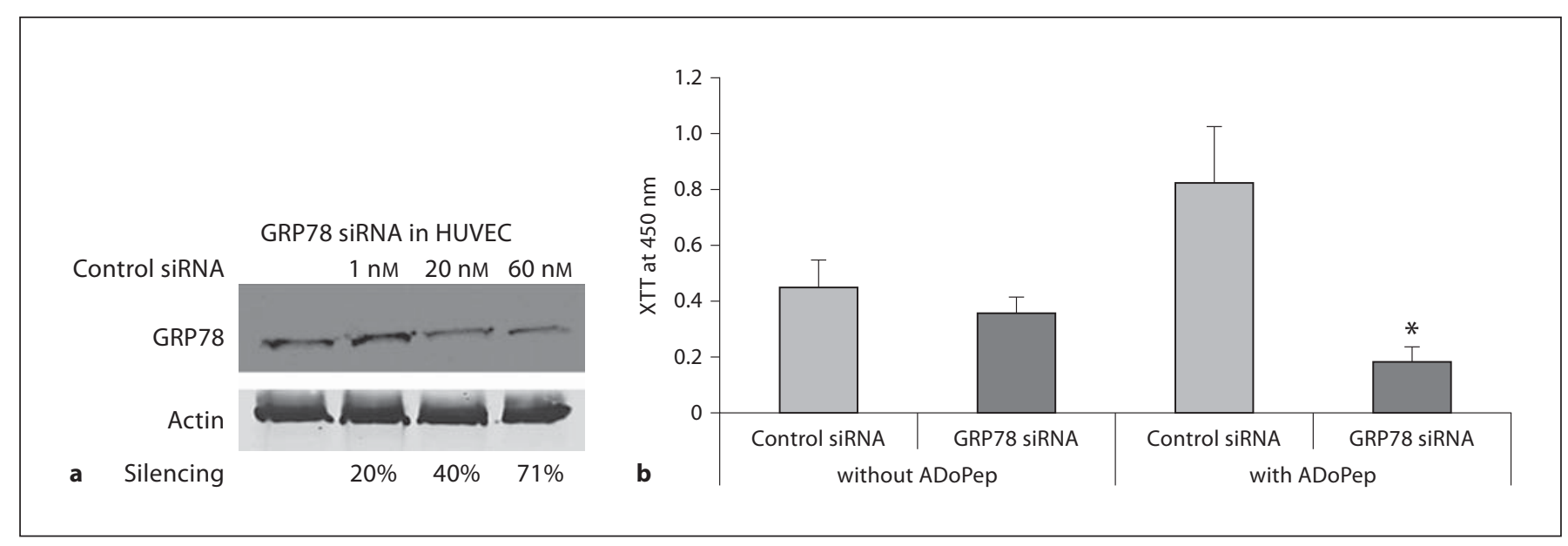

Fig. 8. Effect of ADoPep1 in GRP78 siRNA endothelial cells. Endothelial cells were transfected with scramble-RNA and different concentrations of GRP78-siRNA as described in the Materials and Methods section. Cells were analyzed $48 \mathrm{~h}$ after transfection by SDS-PAGE a Significantly reduced endothelial cell expression of GRP78 by siRNA was obtained at $60 \mathrm{nM}$. GRP78 siRNA representative experiment of 3 independent experiments is shown. b Migration of GRP78 siRNA-transfected or scrambled siRNA- transfected endothelial cells transferred to Boyden chambers. ADoPepl was added to the feeder tray at $10 \mathrm{ng} / \mathrm{ml} \mathrm{ml}$ for $5 \mathrm{~h}$ under hypoxic conditions. Cells that migrated through the membrane were transferred to a 96-well plate and counted by XTT. Mean \pm $\mathrm{SD}$ for 3 independent experiments showed significant inhibition in migration of endothelial cells GRP78 siRNA transfected as compared with scrambled transfected cells $\left({ }^{*} \mathrm{p}<0.05\right)$ with the addition of ADoPep1 as chemoattractant. in cultures of endothelial cells did not induce a significant effect (data not shown) probably due to the threedimensional structure of the large ADAM15 molecules. We assume that under in vivo physiological conditions, disintegration of this protein to peptides might involve the induction of angiogenesis. The rationale of the synthesis of the 3 ADAM15-derived peptides that include the 4 common amino acids in different positions was to compare their angiogenic activity and to select the best natural peptide analogous to the random peptide RoY, identified from a combinatory peptide library.

Although all 3 peptides were found to compete for the same binding determinant, ADoPepl containing the 4 amino acids at the NH2-terminus exhibited the most significant effects. As seen in the Results section, endothelial cell proliferation, migration and tube formation as well as restoration of blood perfusion in the mouse ischemic hind limb induced by ADoPep2 and 3 was not significant in comparison to ADoPep1 and RoY peptide, suggesting the common motif HWRR as responsible for these effects. A comparison of the structure of RoY with ADoPep2 and 3 shows an L-leucine residue flanking the common motif on the NH2-terminus, instead of L-glycine, which may enhance the hydrophobicity of the binding region, thereby blocking the triggering of a signaling cascade [17].
The binding protein on endothelial cells was identified as a heat shock protein GRP78. It is interesting to note that GRP78 was first found to bind the synthetic RoY peptide by screening endothelial cells under hypoxic conditions and after a negative selection on PBL [3]. The negative selection step in the screening might have eliminated peptides targeting VEGF receptors, since they were found to be present also on lymphocytes [18-20], thus enabling the identification of a novel angiogenic target such as GRP78. We have demonstrated that binding to GRP78 induced angiogenesis in a VEGF-independent mechanism; AdoPep1 did not induce KDR (VEGF R2) protein synthesis as well as receptor phosphorylation and RoY (YR) peptide did not induce VEGF receptor gene expression [4]. To confirm the agonistic binding of ADoPep1 to GRP78 for induction of migration, we silenced GRP78 RNA. As described in the results, ADoPepl failed to induce migration in endothelial cells transfected with GRP78 siRNA in contrast to the scrambled siRNA. These data show the necessity of GRP78 expression for ADoPep1 induction of angiogenic processes.

Although heat shock protein GRP78 has long been studied as a molecular chaperone in the endoplasmic reticulum expressed in mammalian cells and has a critical role in cellular integrity [21], its translocation to the plas-

J Vasc Res 2010;47:399-411 409 
ma membrane on different cells was found to have several implications. There, GRP78 has been shown to mediate agonistic binding and signaling leading to increased Akt and ERK1/2 phosphorylation [22, 23]. Under hypoxic conditions, GRP78 exposed on the surface of stimulated endothelial cells was found to be implicated in the angiogenic process. Hypoxia increased the expression of GRP78 on the cell surface, conferring a protective cellular response against stress conditions [24-26], and was also found to induce cell cycle arrest at the G0/G1 phase, resulting in massive cell apoptosis [27]. It is possible that hypoxia-increased membrane GRP78 is a trigger for apoptosis. Therefore, binding of peptide or anti-GRP78 antibody to membrane GRP78 might decrease the stress protein on endothelial cell membranes and reduce apoptosis. This possibility is supported by the finding that the addition of ADoPep1 or anti-GRP78 to endothelial cells inhibited hypoxia-induced apoptosis, but not $\mathrm{CoCl}_{2}$-induced apoptosis (data not shown). In contrast to the pro-angiogenic effects of ADoPepl, peptides of human plasminogen Kringle 5 induced apoptosis and anti-angiogenesis [24]. It is possible that different peptides bind different domains of the GRP78 to induce opposite effects. The addition of ADoPep1 to endothelial cells under hypoxia induced a dramatic decrease in membrane GRP78 after only $15 \mathrm{~min}$, as measured by FACS analysis. This is most likely due to the internalization of the receptor. The internalization of the receptor might have triggered Akt and ERK signaling survival/proliferation pathways, since the addition of ADoPepl to endothelial cells under hypoxic conditions increased Akt and ERK phosphorylation. The implications of specific inhibitors PI3K and MEK confirmed the specific signaling, suggesting that ADoPep binding to GRP78 induces activation of PI3K and MEK pathways. A decrease in GRP78-positive cells was also seen in histological sections from mouse hind limb ischemia treated by the peptide, suggesting that the peptide prevented the hypoxia-induced overexpression in GRP78. In conclusion, data presented here demonstrate a peptide derived from ADAM15 metalloproteinase that activates GRP78 on endothelial cell membranes under hypoxic conditions. This leads to the induction of angiogenesis and the inhibition apoptosis which is partly mediated by the Akt and ERK signaling pathways.

This study contributes to the understanding of angiogenesis by the activation of GRP78 and might serve as a basis for the future development of a protein-derived peptide for the treatment of ischemic diseases.

\section{Acknowledgments}

The authors wish to thank Dr. Maya Levine Arame, DVM, for her excellent technical assistance in the ischemic mouse model. We also wish to thank Mrs. Sara Dominitz for her superb editorial assistance. This study was supported by a research grant from Tel-Aviv University.

\section{References}

1 GlienkeJ,SchmittAO, PilarskyC, Hinzmann B, Weiss B, Rosenthal A, Thierauch KH: Differential gene expression by endothelial cells in distinct angiogenic states. Eur J Biochem 2000;267:2820-2830

2 Ahn A, Frishman WH, Gutwein A, Passeri J, Nelson M: Therapeutic angiogenesis: a new treatment approach for ischemic heart disease. Part II. Cardiol Rev 2009;16:219-229.

3 Hardy B, Raiter A, Weiss C, Kaplan B, Tenenbaum A, Battler A: Angiogenesis induced by novel peptides selected from a phage display library by screening human vascular endothelial cells under different physiological conditions. Peptides 2007;28:691-701.

4 Hardy B, Battler A, Weiss C, Kudasi O, Raiter A: Therapeutic angiogenesis of mouse hind limb ischemia by novel peptide activating GRP78 receptor on endothelial cells. Biochem Pharm 2008;75:891-899.
-5 Fourie AM, Coles F, Moreno V, Karlsson L: Catalytic activity of ADAM8, ADAM15, and MDC-L (ADAM28) on synthetic peptide substrates and in ectodomain cleavage of CD23. J Biol Chem 2003;278:30469-30477.

-6 Horiuchi K, Weskamp G, Lum L, Hammes HP, Cai H, Brodie TA, Ludwig T, Chiusaroli R, Baron R, Preissner KT, Manova K, Blobel CP: Potential role for ADAM15 in pathological neovascularization in mice. Mol Cell Biol 2003;23:5614-5624.

7 Koji Eto K, Huet C, Tarui T, Kupriyanov S, Liu HZ, Puzon-McLaughlin W, Zhang XP, Sheppard D, Engvall E, Takada Y: Functional classification of ADAMs based on a conserved motif for binding to integrin. J Biol Chem 2002;277:17804-17810.

8 Trochon-Joseph V, Martel-Renoir D, Mir LM, Thomaidis A, Connault E, Li H, Grenet C, Fauvel-Lafeve F, Soria J, Legrand C, Soria C, Perricaudet M, Lu H: Evidence of antiangiogenic and antimetastatic activities of the recombinant disintegrin domain of metargidin. Can Res 2004;64:2062-2069.
9 White J: ADAMs: modulators of cell-cell and cell-matrix interactions. Curr Opin Cell Biol 2003; 15:598-606

10 Bohm BB, Aigner T, Roy B, Brodie TA, Blobel $\mathrm{CP}$, Burkhardt H: Homeostatic effects of the metalloproteinase disintegrin ADAM15 in degenerative cartilage remodeling. Arthritis Rheum 2005;2:1100-1109.

11 Charrier-Hisamuddin L, Laboisse CL, Merlin D: ADAM-15: a metalloprotease that mediates inflammation. FASEB J 2008;22:641653.

12 Martin J, Eynstone LV, Davies M, Williams JD, Steadman R: The role of ADAM15 in glomerular mesangial cell migration. J Biol Chem 2002;277:33683-33689.

13 Jaffe EA, Hoyer LW, Nachman RL: Synthesis of antihemophilic factor antigen by cultured human endothelial cells. J Clin Invest 1973; 52:2757-2764. 
14 Cao R, Brakenhielm E, Pawliuk R, Wrarjaro D, Post MJ, Wahlberg E: Angiogenic-synergism, vascular stability and improvement of hind-limb ischemia by a combination of PDGF-BB and FGF-2. Nat Med 2003;9:604613.

15 Sun Q, Chen RR, Shen Y, Mooney DJ, Rajagopalan S, Grossman PM: Sustained vascular endothelial growth factor delivery enhances angiogenesis and perfusion in ischemic hind limb. Pharm Res 2005;22:110-1116.

-16 Couffinhal T, Silver M, Zheng LP, Kearney M, Witzenbichler B, Isner JM: Mouse model of angiogenesis. Am J Pathol 1998;152:16671679.

$>_{17}$ Inoue $\mathrm{H}$, Lin L, Lee X, Shao Z, Mendes S, Snodgrass-Belt P, Sweigard H, Engber T, Pepinsky B, Yang L, Beal MF, Mi S, Isacson O: Inhibition of the leucine-rich repeat protein LINGO-1 enhances survival, structure, and function of dopaminergic neurons in Parkinson's disease models. Proc Natl Acad Sci USA 2007; 104:14430-14435.

${ }_{18}$ Koutroubakis IE, Tsiolakidou G, Karmiris $\mathrm{K}$, Kouroumalis EA: Role of angiogenesis in inflammatory bowel disease. Inflamm Bowel Dis 2006;12:515-523.
19 Shin JY, Kim JK, Kim B, Yun IH, Park CG: Expression of vascular endothelial growth factor receptor 1 (VEGFR-1), but not VEGFR-2 in activated lymphocytes and its function in response to VEGF. J Immunol 2007;178:49.28.

-20 Stepanova OI, Krylov AV, Lioudyno VI, Kisseleva EP: Gene expression for VEGF-A, VEGF-C, and their receptors in murine lymphocytes and macrophages. Biochemistry (Mosc) 2007;72:1194-1198.

21 Lee AS: GRP78 induction in cancer: therapeutic and prognostic implications. Can Res 2007;67:3496-3499.

22 Misra UK, Deedwania R, Pizzo SV: Activation and cross talk between Akt, NF- $\kappa \mathrm{B}$, and unfolded protein response signaling in 1-LN prostate cancer cells consequent to ligation of cell surface-associated GRP78. J Biol Chem 2006;281:13694-13707.

23 Misra UK, Pizzo SV: Heterotrimeric G $\alpha$ q11 co-immunoprecipitates with surface-anchored GRP78 from plasma membranes of $\alpha_{2} M^{*}$-stimulated macrophages. J Cell Biochem 2008;104:96-104.
24 Davidson DJ, Haskell C, Majest S, Kherzai A, Egan DA, Walter KA, Schneider A, Gubbins EF, Solomon L, Chen Z, Lesniewski R, Henkin J: Kringle 5 of human plasminogen induces apoptosis of endothelial and tumor cells through surface-expressed glucoseregulated protein 78. Can Res 2005;65:46634672.

25 Reddy RK, Mao C, Baumeister P, Austin RC, Kaufman RJ, Lee AS: Endoplasmic reticulum chaperone protein GRP78 protects cells from apoptosis induced by topoisomerase inhibitors: role of ATP binding site in suppression of caspase-7 activation. J Biol Chem 2003;278:20915-20924.

-26 Song MS, Park YK, Lee JH, Park K: Induction of glucose-regulated protein 78 by chronic hypoxia in human gastric tumor cells through a protein kinase C-epsilon/ ERK/AP-1 signaling cascade. Can Res 2001; 61:8322-8330.

27 Li C, Issa R, Kumar P, Hampson IN, LopezNovoa JM, Bernabeu C, Kumar S: CD105 prevents apoptosis in hypoxic endothelial cells. J Cell Sci 2003;116:2677-2685. 